Supporting information

\title{
Mn-Polyacrylonitrile Nanofibers Decorated with Co-Metal Organic Frameworks as Precursors of CoMnOx Catalysts for the Combustion of Toluene
}

\author{
Weigao Han ${ }^{\mathrm{a}, \mathrm{b}}$, Fang Donga, Weiliang Han ${ }^{\mathrm{a}}$, Zhicheng Tang ${ }^{\mathrm{a}^{*}}$ \\ (a. State Key Laboratory for Oxo Synthesis and Selective Oxidation, National \\ Engineering Research Center for Fine Petrochemical Intermediates, Lanzhou \\ Institute of Chemical Physics, Chinese Academy of Sciences, Lanzhou 730000, PR \\ China \\ b. University of Chinese Academy of Sciences, Beijing 100039, PR China)
}

\footnotetext{
${ }^{*}$ Corresponding author: State Key Laboratory for Oxo Synthesis and Selective Oxidation, and National Engineering Research Center for Fine Petrochemical Intermediates, Lanzhou Institute of Chemical Physics, Chinese Academy of Sciences, Lanzhou 730000, PR China.

E-mail address: tangzhicheng@licp.cas.cn
} 


\section{Characterization of materials}

The morphology of the samples was evaluated with transmission electron microscope (TEM). The images of TEM and selected-area electron diffraction patterns were obtained under a microscope of $200 \mathrm{kV}$ using FEI TECNAIG $\square$. Power X-ray diffraction (XRD) analysis was finished at $60 \mathrm{kV}$ and $55 \mathrm{~mA}$ with a scanning speed of $0.5^{\circ} \mathrm{min}^{-1}$. The $2 \theta$ of wide-angle ranged from $10^{\circ}$ to $80^{\circ}$. Raman scattering was done by using a Laboratory Human Resources Evolution Raman spectrometer (BX41). The XPS measurement was done on a VG ESCALAB 210 Electron Spectrometer $(\mathrm{Mg} \mathrm{K} \alpha$ radiation; $\mathrm{h} v=1253.6 \mathrm{eV})$. The specific surface area and the average pore diameter of the catalysts were measured by nitrogen adsorption with a micromeritics ASAP2010 instrument.

For $\mathrm{H}_{2}-\mathrm{TPR}$, a $50 \mathrm{mg}$ sample was pre-treated at an atmosphere of nitrogen. The temperature was increased from room temperature to $350{ }^{\circ} \mathrm{C}$ with a heating rate of $10{ }^{\circ} \mathrm{C} \min ^{-1}$. When it cooled down to room temperature, the temperature was increased from room temperature to $900{ }^{\circ} \mathrm{C}$ with a heating rate of $10{ }^{\circ} \mathrm{C} \mathrm{min}-1$. A reducing gas of $5 \%$ vol. $\mathrm{H}_{2}$ and $95 \%$ vol. $\mathrm{N}_{2}$ was passed on the sample at the same time.

For $\mathrm{O}_{2}$-TPD, an $80 \mathrm{mg}$ sample was pre-treated at an atmosphere of nitrogen. The temperature was increased from room temperature to $350{ }^{\circ} \mathrm{C}$ with a heating rate of $10{ }^{\circ} \mathrm{C} \mathrm{min}^{-1}$. And it was treated for $90 \mathrm{~min}$. When it cooled down to room temperature, the temperature was increased from room temperature to $30^{\circ} \mathrm{C}$ for 60 min with a gas of $5 \%$ vol. $\mathrm{O}_{2}$ and $95 \%$ vol. $\mathrm{N}_{2}$ passing through. Finally, the 
temperature was increased from room temperature to $900{ }^{\circ} \mathrm{C}$ with a heating rate of $10{ }^{\circ} \mathrm{C} \mathrm{min}^{-1}$.

For $\mathrm{NH}_{3}$-TPD, an $80 \mathrm{mg}$ sample was pre-treated at an atmosphere of nitrogen. The temperature was increased from room temperature to $350{ }^{\circ} \mathrm{C}$ with a heating rate of $10{ }^{\circ} \mathrm{C} \mathrm{min}^{-1}$. And it was treated for $90 \mathrm{~min}$. When it cooled down to room temperature, the temperature was increased from room temperature to $50{ }^{\circ} \mathrm{C}$ for 60 min with a gas of $5 \%$ vol. $\mathrm{NH}_{3}$ and $95 \%$ vol. $\mathrm{N}_{2}$ passing through. Finally, the temperature was increased from room temperature to $900{ }^{\circ} \mathrm{C}$ with a heating rate of $10{ }^{\circ} \mathrm{C} \mathrm{min}^{-1}$.

\section{Catalytic activity measurements}

The catalytic oxidation of toluene was evaluated by using a fixed-bed flow reactor operating at steady-state flow mode. Then, $0.4 \mathrm{~g}$ catalysts (40-60 mesh) and 0.7 g quartz sand (40-60 mesh) were mixed uniformly. They were put onto the reactor. The reaction gas containing VOCs (3000 ppm) was generated by bubbling air through a VOC saturator, and then passed through the reactor with a weight hourly space velocity (WHSV) of $30000 \mathrm{~mL} \mathrm{~g}^{-1} \mathrm{~h}^{-1}$. The first temperature was $100{ }^{\circ} \mathrm{C}$. The activity was measured per $20{ }^{\circ} \mathrm{C}$. Before each test, it needed to stabilize for $2 \mathrm{~h}$. Reactants and products were analyzed with an online GC-6820 gas chromatograph with a flame ionization detector, Conversion was defined as:

$$
C_{\text {toluene }}=\frac{[C]_{\text {inlet }}-[C]_{\text {outlet }}}{[C]_{\text {inlet }}} \times 100 \%
$$




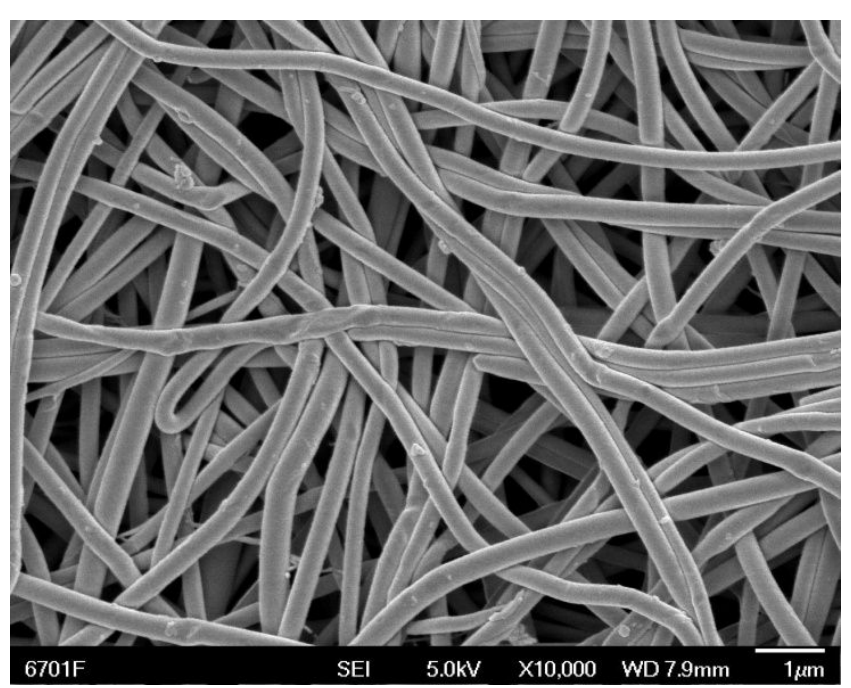

Fig. S1 The pure PAN nanofibers without PBA adding in. 


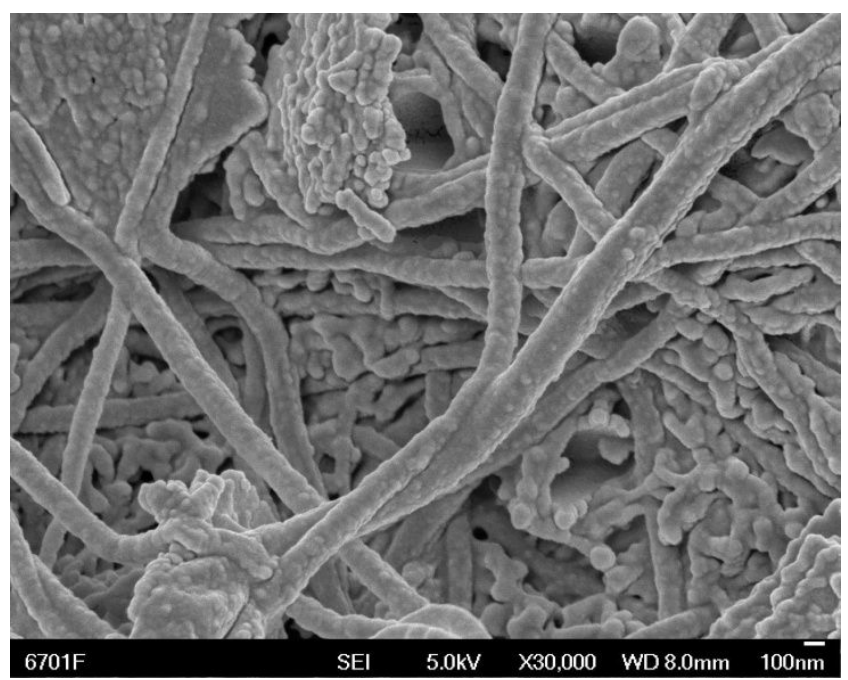

Fig. S2 The rough Mixed-PBA/PAN sample, which was composed of many nanoparticles and some nanosheets. 


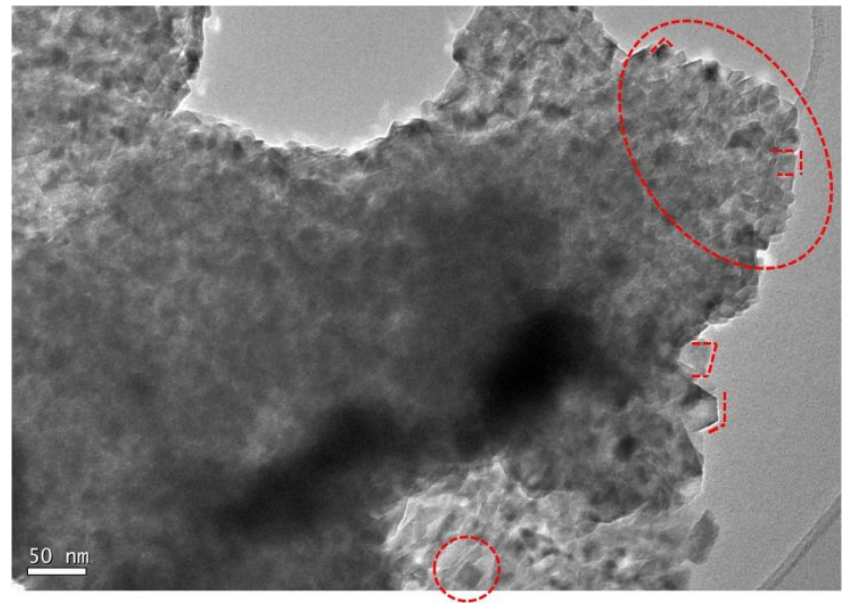

Fig. S3 The enlarged image of calcined Mixed-CoMnO${ }_{x} / \mathrm{MnO}_{y}$ sample, which was consisted of many little nanocubes. 


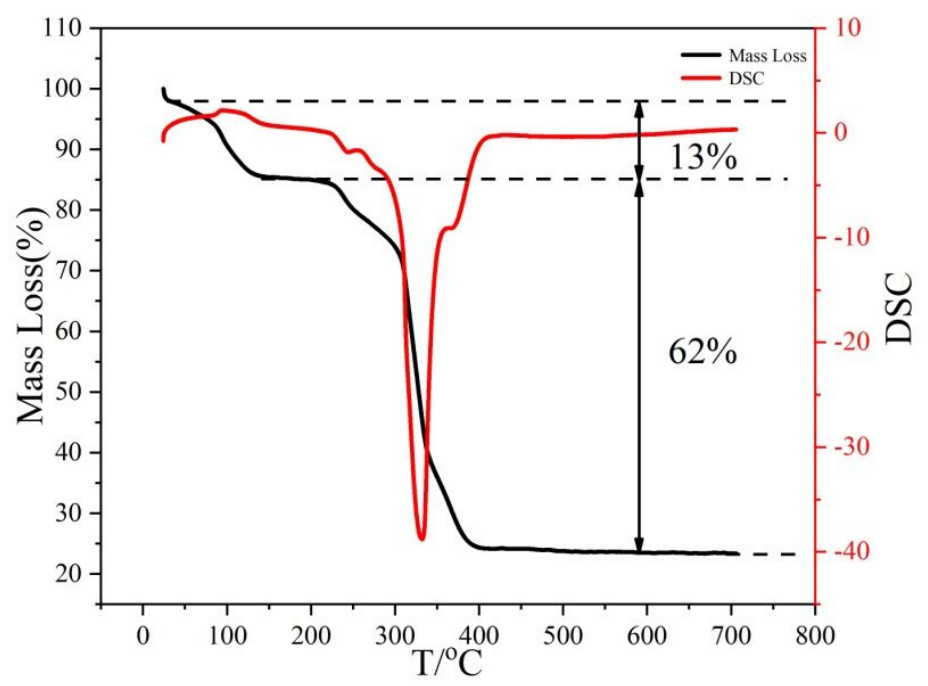

Fig. S4 The TG results of In-CoMnO ${ }_{\mathrm{x}} / \mathrm{MnO}_{\mathrm{y}}$ samples. 


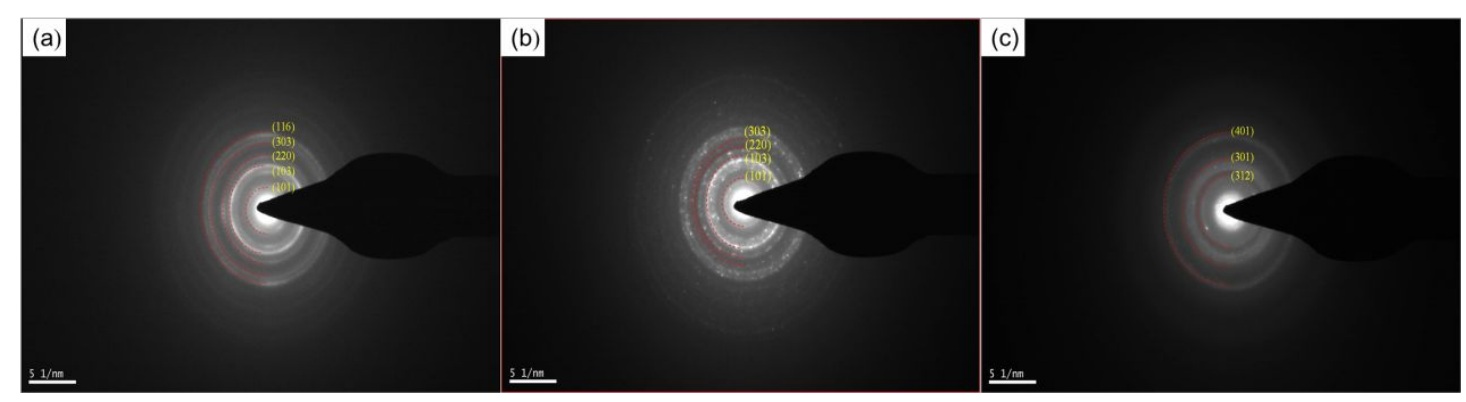

Fig. S5 The SEAD pattern of the In-CoMnO $/ \mathrm{MnO}_{y}(\mathrm{a})$, Out-CoMnO${ }_{\mathrm{x}} / \mathrm{MnO}_{\mathrm{y}}(\mathrm{b})$ and Mixed-CoMnO $\mathrm{x} / \mathrm{MnO}_{\mathrm{y}}$ (c) samples. 

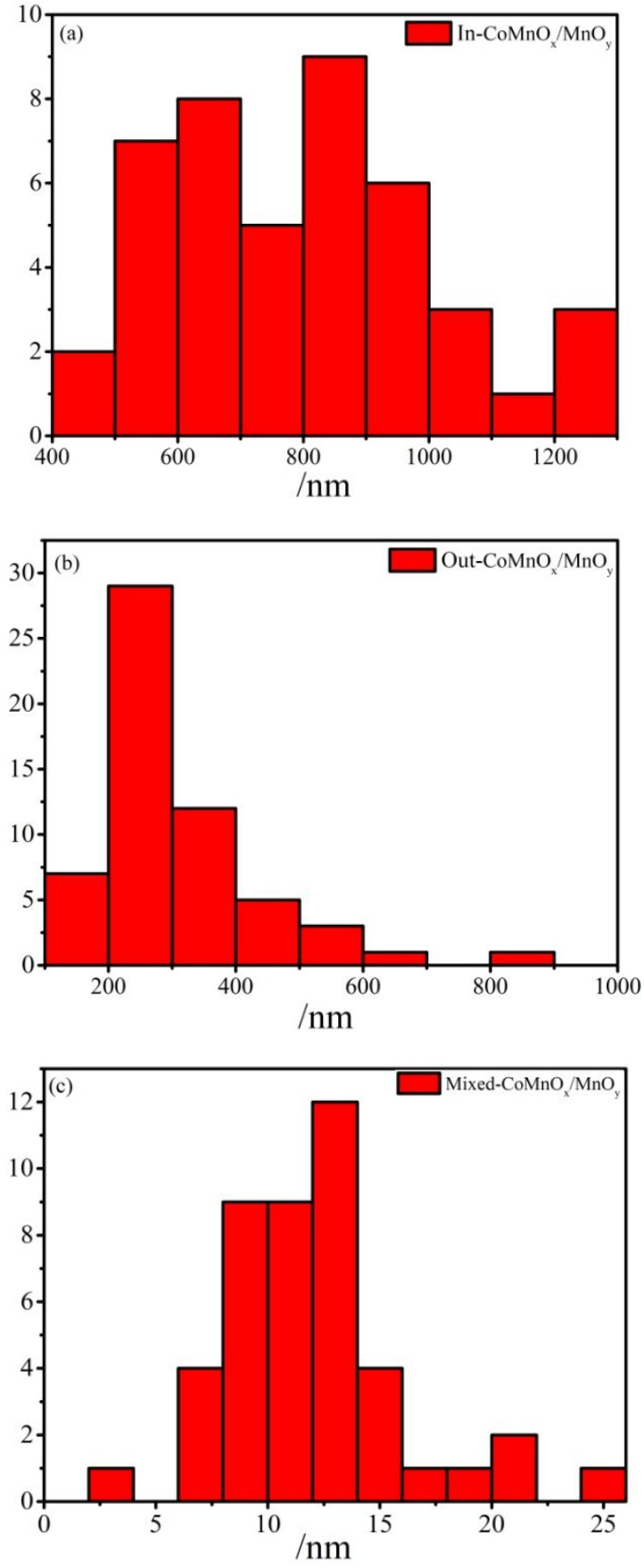

Fig. S6 The grain distribution diagrams of the In- $\mathrm{CoMnO}_{\mathrm{x}} / \mathrm{MnO}_{\mathrm{y}}(\mathrm{a})$, Out-CoMnO ${ }_{\mathrm{x}} / \mathrm{MnO}_{\mathrm{y}}$ (b) and Mixed-CoMnO $\mathrm{x}_{\mathrm{x}} / \mathrm{MnO}_{\mathrm{y}}$ (c) samples. 

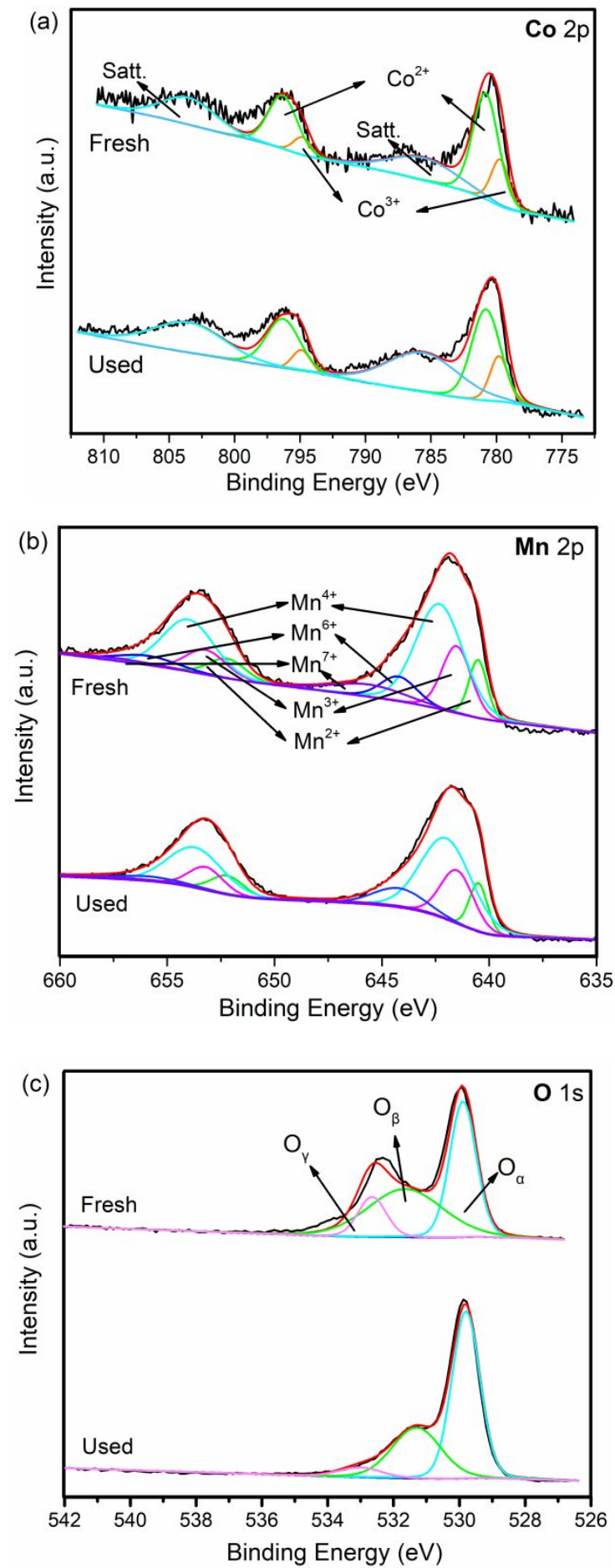

Fig. S7 XPS spectra of the used and fresh In-CoMnOx/MnOy samples: Co 2p (a), O $1 \mathrm{~s}(\mathrm{~b}), \mathrm{Mn} 2 \mathrm{p}(\mathrm{c})$. 